This is the authors' version of this work. It was later published as:

Susan L. Whatman \& Parlo Singh, Physical Education and Sport

Pedagogy (2013): Constructing health and physical education curriculum

for indigenous girls in a remote Australian community, Physical Education and Sport Pedagogy, DOI: 10.1080/17408989.2013.868874

http://www.tandfonline.com/eprint/ityWdntQRIW7Sp4draSP/full

Copyright: Taylor \& Francis, 25th November, 2013

\title{
Constructing Health and Physical Education (HPE) Curriculum for Indigenous Girls in a Remote Australian Community
}

Susan L. Whatman (a), Parlo Singh (b)

a) School of Education and Professional Studies, Griffith University, Australia

b) Griffith Institute for Educational Research, Griffith University, Australia.

School of Education and Professional Studies, Gold Coast Campus, Griffith University QLD 4222, Australia. Phone +61 (7) 55529240 E-mail: $\underline{\text { s.whatman@griffith.edu.au }}$ 


\title{
Constructing Health and Physical Education (HPE) Curriculum for Indigenous Girls in a Remote Australian Community
}

\author{
Background: \\ Over the last 20 years, curriculum development in Health and Physical Education \\ [HPE] (or Physical Education [PE], Physical Education and Health [PEH], Sport \\ Education [SE] as it variously called) has repeatedly attempted to address issues \\ of equity and social inclusion (Evans, 2013). Why then does systemic \\ educational disadvantage persist, and the poorest members of society acquire less \\ privileged and privileging forms of HPE knowledge, skills and bodily \\ dispositions? What constitutes relevant and responsive health and physical \\ education curriculum for which groups of students remains a site of considerable \\ contestation.
}

Recent debates in the Australian media and Government policy initiatives have reinvigorated the 'educational disadvantage' perspective on Indigenous education in general, impacting upon curriculum decision-making in Health and Physical Education (HPE). Debates such as these focus upon the social, material and cultural circumstances of students as the explanation for educational achievement (or lack thereof), where Indigenous students are defined more by what they 'lack' than what the Western schooling system fails to deliver (Nakata 2007).

Purpose: At a time when significant changes are being suggested to HPE curricula with the development of the Australian (National) Curriculum (see http://consultation.australiancurriculum.edu.au/), this paper is an attempt to refocus the analysis of education for Indigenous students in Australia upon the power and control relations operating within schools, rather than external social relations, using principles of pedagogic discourse from the sociological theories of Basil Bernstein (2000). The paper contributes to the growing corpus of studies on the social relations within schooling which constitute HPE curriculum, and the possibilities for interrupting systemic social inequity through the redesign of school curriculum and pedagogy (see Evans \& Davies, 2008; Lundvall \& Meckbach, 2008; McCuaig \& Hay, 2012; Nyberg \& Larsson, 2012).

Methods: Using critical ethnographic methodology (Carspecken 1996), a single, intrinsic case study of a school in a Torres Strait Islander community in Australia was undertaken (Stake 1995). Document collation, observation and researcher notes, and individual and focus group interviews with stakeholders comprised the data collection methods. Stakeholders including female students $(n=13)$, teachers $(n=7)$, parents $(n=2)$, school administrators $(n=4)$, regional education staff $(n=2)$, community advisors in education and health $(n=2)$, and regional health professionals $(n=6)$ comprised the group of key informants and research participants.

Discussion \& Conclusion: Government policy initiatives have reinforced a dominant and persistently negative discourse about 'educational disadvantage' when representing Aboriginal and Torres Strait Islander (Indigenous) students and educational outcomes. This paper challenges these negative discourses and focuses attention on the social relations within schooling which constitute the 'what' and 'how' of HPE curriculum, contributing to the large corpus of 
Bernsteinian studies of HPE curriculum which 'look beneath the surface appearances of progress and innovation, to how inequities endure, despite rhetorical claims to the contrary that they have been eroded or have disappeared' (Evans \& Davies, 2008, 205). It also reveals the important contribution that Indigenous communities and educators have and continue to make to curriculum decision-making in HPE for Indigenous Australian students.

Keywords: health and physical education curriculum, Indigenous Australians, pedagogic discourse, Bernstein. 


\section{Introduction}

Health and Physical Education (HPE) curriculum in the UK, Europe and Australia appears to be the negotiated product of 'a profession in progress, having agency and momentum, addressing issues of equity and inclusion, all of which must be a good thing' (Evans, 2013, 76). Yet as Evans and Davies (2008, 200) argue social class continues to matter and 'facts around health, longevity, opportunity and wealth tend to speak for themselves and have a powerful bearing on people's lives.' Indeed, Evans and Davies $(2008,200)$ argue that policy, research and practice in Physical Education and Health (PEH) has tended to 'obscure and sanitise' social class issues through a language that focuses on "'lifestyle', 'partnerships', 'disadvantage' and 'social exclusion"”, a neo-liberalist construction of the "rational self-managing citizens' who voluntarily choose, are responsible for and bring about their own good health (Macdonald, 2011, 38). Educational equity thus shifts within this discursive framing from a social or collective responsibility to the responsibility of individuals with the right to make choices and take responsibility for their own bodies. In addition, PEH policy discourses respond repeatedly to manufactured media crises. As Evans (2013, 83) argues:

It is not that 'health' crisis has displaced earlier crisis policy around sport. To the contrary, sport and health crises now comfortably comingle and not only in central Government rhetoric around the purposes of PE but in the discourses of all the communities of practice - sport, physical recreation, leisure, health - that have a vested interest in PE. Together they provide a powerful rationale for the place of PE in schools.

The focus of this paper is on the structuring of HPE curriculum for Indigenous Australian girls in a remote, low socio-economic status (LSES) community. It 'looks beneath the surface appearances of progress and innovation, to how inequities endure, despite rhetorical claims to the contrary they have been eroded or have disappeared' Evans \& Davies, 2008, 205). It contributes to research in Physical Education (PE), $\mathrm{PEH}$, and HPE by theorising the politics of school curriculum negotiation and implementation and thus focusses attention on the immediate educational needs of children and young people rather than on out-of-school factors such as 'attendance rates', 'post school options' and so forth. Specifically, it focuses on 'what constitutes “education”, “educability” and children's opportunities to experience these things' in its attention to the what, how, why and when of HPE school curriculum (Evans \& Davies, 
2008, 206). We are also focusing particularly on the health education (HE) strand of HPE. As one strand of three in the Queensland HPE Curriculum, which also integrates physical activity and personal development, mandated up to Year Ten (see http://www.qsa.qld.edu.au/7294.html), health education primarily is the responsibility of a PE specialist teacher. At primary school level, classroom teachers tend to overlook their potential contribution to HE in an already crowded curriculum, further pressured by national 'high stakes testing' agendas (Macdonald, 2011, 36) while approximately one quarter of secondary schools offer Senior HE alongside Senior PE beyond the $\begin{array}{lllllll}\text { compulsory } & \text { years } & \text { of } & \text { HPE }\end{array}$ http://www.qsa.qld.edu.au/downloads/publications/qsa_stats_sen_subjects_2012.pdf).

The construction and implementation of HE is further complicated in this study by the intersections of gender, race, class and regional/remote contextual factors, all of which has to be negotiated by PE specialist teachers who possibly lack specialist HE training and pedagogical knowledge around working with Indigenous students and contexts (author citation suppressed, 2011). Interestingly, Williams, Hay \& Macdonald (2012, 407) note that few Queensland schools outsource HE expertise in their curriculum 'space' meaning the HPE teachers are generally willing, or expected to teach this knowledge themselves.

Recent debates in the Australian media and Government policy initiatives have reinvigorated the 'educational disadvantage' perspective on Aboriginal and Torres Strait Islander (Indigenous) education. Debates such as these focus upon the social, material and cultural circumstances of students as the explanation for educational achievement (or lack thereof), where Indigenous students are defined more by what they 'lack' than what the Western schooling system fails to deliver (Nakata 2007, 2001). This paper attempts to refocus the analysis upon the power and control relations structuring the selection and organisation of knowledge constituting the school curriculum of health and physical education (HPE) for Indigenous girls in a remote community. 


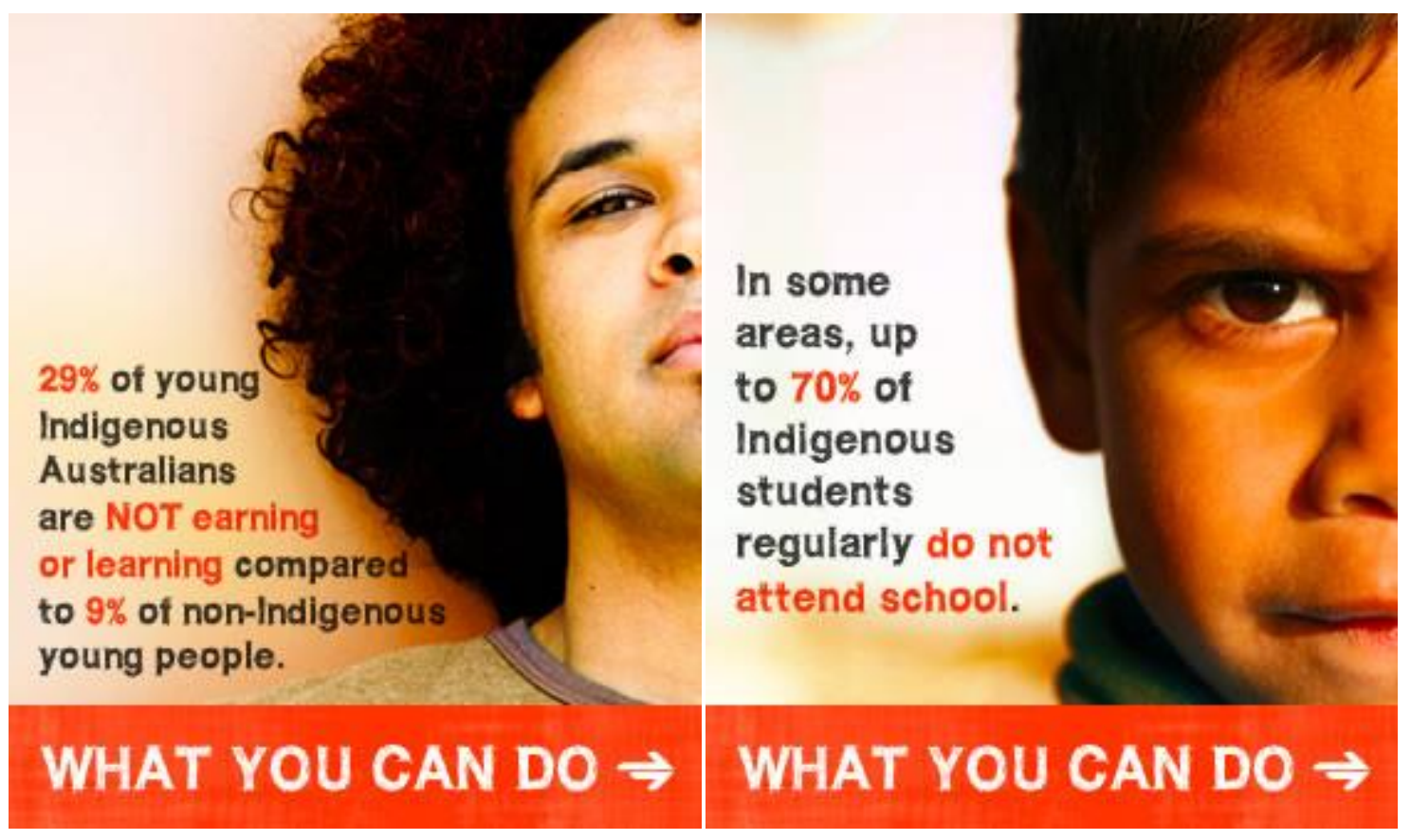

Figure One. Media and popular representations of Indigenous learners (from www.generationon.org.au)

Australian news headlines reinforce a common and easily recognisable representation of Indigenous students as being the 'most lacking' and 'most behind' in all educational benchmarks, particularly in rural and remote schools and communities. Focusing the research gaze upon the social, cultural, psychological and material circumstances of Indigenous students has resulted in a plethora of government sponsored and academic publications in what it is about the Indigenous student (and their families/communities) that causes educational underachievement (Mellor and Corrigan 2004). This 'research gaze' of 'what's wrong with Indigenous people' has informed Government policy in many portfolios, but most particularly in Education. In 2004, Mellor and Corrigan presented a comprehensive review of contemporary research into Indigenous education, summarising the following tendencies:

Indigenous education research has been to an extent isolated from the broader research discourses over teacher quality (and) ongoing professional development... Indigenous education has not been integrated with discourses in other disciplines such as...sociology and...Research has focused predominantly on 'problems' (Paul Hughes, Foreword in Mellor and Corrigan 2004, v). 
Critique of Indigenous student engagement with HPE is quite rare in the Australian educational landscape, but what is canvassed generally begins with a premise that the approach/project/research focus under discussion is 'essential' because health and educational (or housing, or economic, or any other social indicator) benchmarks for Indigenous students fall well below non-Indigenous student benchmarks (see, for example, Abbott et al., 2008.) These indicators are real and it is not the purpose of this paper to dispute them. Our point is that what Indigenous students are perceived to 'lack' shapes the scope of the discussion to follow. We want to discuss this phenomenon in more detail here to contextualise the curriculum decision-making landscape in Australia as it impacts on HPE.

In 2008, the Australian Government hosted the 2020 Summit which included many respected educators, both Indigenous and non-Indigenous. Their brief was to highlight the most pressing issues in Indigenous education and come up with a list of new, daring, thought-provoking and radical approaches to generate a positive shift in those issues. The forum itself did contain many ideas that deviated from the dominant representation of the underachieving Indigenous student/community, but when it came time to collate these ideas and approaches into some sort of strategy or policy document, the dominant view 'lacking unknowledgeable underachiever' reasserted itself, as evidenced by the following statement:

Education is a fundamental pre-condition to a person being equipped to choose the kind of life they want to live. If young Indigenous Australians have no comprehension of the wider world, they cannot make an informed decision about how to engage with that world. How can we improve the educational outcomes for young Indigenous Australians so that they can make these choices? (http://www.australia2020.gov.au/topics/indigenous.cfm)

The summit concluded with the following 'unanswered questions', to frame future

Government action:

(1) What is required for Australians to come to understand the complexity of Indigenous disadvantage, so that they will have a better understanding of the resources and timeframes required to close the gap?

(2) What would improve access to mainstream services for Indigenous Australians living in urban and regional areas?

(3) What targeted interventions have the best hope of achieving change in remote communities?

(4) What is the role of Indigenous leadership development? 
(5) What can be done to best promote and preserve Indigenous culture, languages and traditions?

(6) Where will Indigenous culture be placed in 2020? What is the Indigenous role in what Australia as a whole aspires for in terms of identity and culture?

(7) What is the role for non-Indigenous Australians in working with Indigenous communities towards shared goals? (http://www.australia2020.gov.au/topics/indigenous.cfm)

Moreton-Robinson $(2004,81)$ has described how many non-Indigenous researchers and educators perceive themselves as 'the knowers' and Indigenous people as 'objects to be known'. Point number one above especially highlights this perception; that nonIndigenous Australians will be able to 'fix' Indigenous education if only they can know everything about Indigenous people and communities (as objects to be fixed). Indigenous people are also ironically singled out as needing to show leadership on the issue, implying that they have not previously shown any as indicated in point number four, whilst being simultaneously portrayed as disadvantaged victims unable to improve their own educational outcomes (points three and five). Point Seven - what can nonIndigenous people do? - is both vague and disingenuous, given the vast amounts of educational research already conducted, and a long standing national statement that clearly identifies the need for Indigenous power and control over educational decisionmaking.

\section{Government Priorities - the National Indigenous Education Statement}

The current National Indigenous Education Statement has evolved since 1989 (DEET 1989) around four common goals - involving Indigenous people in educational decision-making, providing equal access to all levels of education to the same extent as other Australians in a relevant and enjoyable way, enabling fair educational results, and the appreciation of shared history and Indigenous cultures by all Australians (http://www.deewr.gov.au/Indigenous/HigherEducation/Programs/Pages/IndigenousEdu cationStatement.aspx ). Educational providers are expected to report upon how they have established effective arrangements for the participation of Indigenous peoples in educational decision-making, including the employment of Indigenous people in the sector, account for the numbers of students participating across all levels of education (enrolment, retention, achievement and graduation), comparatively reported against 
non-Indigenous student outcomes. The key issue to remember here is that Indigenous student success is tied to being favourably compared (by non-Indigenous people) to non-Indigenous student success. As such, the policy does not provide scope to explore how notions of cultural relevance and Indigenous people's understandings of a successful education inform educational decision-making when strategic initiatives and outcomes are only measured on non-Indigenous terms.

\section{Learn Earn Legend! Supported by the Australian Government Stay at School Get that Job Be a Legend}

Figure Two. Logo of the Australian Government's Indigenous Education Statement

Consistent with the popular view of the Indigenous learner presented in Figure One, the image above is the Australian government logo for the National Indigenous Education Strategy. 'Stay at school - get that job' shouts the heading. Are Australian educators left in any doubt as to the presumption behind Indigenous student 'failure'? As Nakata (1993) warned when the first Indigenous education strategy was launched in 1989, the policy effectively diverted attention away from what schools were actually doing to imply that success is primarily a matter of attendance:

...while attention focuses on equality (and) access to education services...the specific social and material conditions of discriminatory practices underway in the schooling process remain unproblematised in the theorisation of 'low performances' (Nakata 1993, 339).

State Government Education policy also reiterates the assumption that access and participation is behind Indigenous student underachievement despite the best efforts and intentions of state education providers. The Queensland Government's 'Partners for Success' strategy (DETA, 2000) relates to the provision of state education in Indigenous education in city and remote regions, while the 'Bound for Success' (DETA 2005) strategy has been negotiated specifically with Far Northern Queensland communities and the Torres Strait, which impacts upon the school discussed in this paper. The preamble to 'Bound for Success' argues: 
that children and young people living in the Torres Strait face greater challenges than others in accessing education and achieving academic success. The strategy responds to these challenges by outlining priority areas for action including increasing student accommodation on (the) Island, an improved pre-Prep early education program for young children, a consistent regional school curriculum for all state schools in the Torres Strait and clearer, more regular opportunities for consultation with Torres Strait Island communities on important education issues.

http://education.qld.gov.au/schools/indigenous/strategies/bfs-torres-strait.html (DETA 2005, i).

Indigenous educational consultation is articulated in the national and state policies but the regional education strategy for the Torres Strait specifies a particular way in which curricular reform should occur. We believe that this kind of mandate increases the possibilities for Bernsteinian theory to contribute to analytic research on relevant and responsive HPE curricula for Indigenous girls.

\section{The Less Popular View of Indigenous Education - Indigenous views on relevant and responsive Indigenous education}

Respected Indigenous educators, specifically from the state of Queensland, such as Nakata (1993; 2007), Tripcony (2000), Moreton-Robinson (2004), Herbert (2006), , Martin (2007), White (2009), Hart (2012), Ketchell (2012) and Phillips (2012) have argued that focusing upon what is 'lacking' in the Indigenous student positions Whiteness in the education system as 'neutral' and 'invisible' (Moreton-Robinson 2004; Phillips, 2005), and 'not responsible' (Hart, 2012) for Indigenous student underachievement, placing the blame squarely on the collective shoulders of the students themselves, their parents, their extended families, their communities and their culture. So this approach ironically, but as a deliberate practice, according to MoretonRobinson $(2004,81)$ 'deploys the Cartesian model to separate the racialised white body of the knower from the racialised discourse and knowledge produced by its mind'. It therefore renders Indigenous culture as the reason for failure in the Indigenous student, but obscures and exonerates the role of non-Indigenous culture permeating educational systems in that same failure. Nakata $(1993 ; 2001 ; 2007)$ has long argued that the prevailing perception that Indigenous people 'lack' what they need to succeed, and the 
real lack of a focus upon what goes on inside schools, masks the true barriers to Indigenous student success:

Along with Aboriginal people, I think Islanders have probably at some stage or other been represented as having lacked everything there is to have...(we) lacked in terms of intellect, language, education, finance, social skills...we lacked as fathers and mothers we lacked as children, we lacked as students - we lacked information and mainstream experiences. It has been written from the time of the first anthropological expedition by Haddon in the 1880s and over 100 years later, you name it, we lack it (Nakata 2001, $341)$.

Nakata's (2001) argument to cease talking about what Indigenous students 'lack' in school and Herbert's (2006) deliberate standpoint to only represent Indigenous student success in her research on tertiary education echoes closely a stance taken by Bernstein in 1971, when he critiqued the policy initiatives of the day and the subsequent treatment of working class students in British schooling systems:

I do not understand how we can talk about offering compensatory education to children who, in the first place, have as yet not been offered an adequate educational experience...The concept of 'compensatory education' serves to direct attention away from the internal organization of the school and the educational context of the school, and focus our attention upon the families and the children...(it) implies that something is lacking in the family and so in the child...and the children become little deficit systems (Bernstein 1971, 191-192).

It was this standpoint, the recognition that schools tend to 'blame the victim' instead of their own internal processes, that lead to our decision to investigate health education curriculum decision-making for girls using a Bernsteinian theoretical framework. Bernstein's statement $(1996, x x)$ about democracy and pedagogic rights, that 'people and students must feel that they have a stake in the school and confidence that the arrangements in the school will realise or enhance this stake', also resonated with school/community participation theory which also framed the study (see for example Soliman 1995, Heslop 1998, Stewart 1999, 2009).

\section{Methodology}

Conventional ethnography aims to describe 'what is', while critical ethnography asks 'what could be' (Thomas, 1993, p.4). Conventional ethnographers often speak for their research subjects to an audience of other researchers. By contrast, critical ethnographers claim to speak to a research audience on behalf of research subjects, to 
empower and give authoritative voice to the concerns of what is often an oppressed group in society.

Critical ethnographic researchers share a concern with social inequalities and social theory, including the nature of social structure, power, culture and human agency (Carspecken 1996, 3). In this sense, culture is regarded not only as a social construction, but also as a site within which the social relations between groups allow some groups to enhance their own authority, while regulating others, and to control the social space for their own benefit (Carspecken and Apple 1992, 508). Culture and power, then, 'are not part of different language games but, rather, form an indissoluble couplet in daily life' (Carspecken and Apple 1992, 508). Stake (1995, xi) argued that case study is the study of the particularity and complexity of a single case, coming to understand its activity within important circumstances. This paper is thus drawn from an intrinsic and instrumental case study of the nature and extent of community participation in health education curriculum decision-making for girls. The reasons for choosing the school were based upon an intrinsic interest in Torres Strait Islander education, and the focus on girls was to conform with local research protocols and customs. However, it is accepted that what was disclosed through the research activity may be of broader interest to researchers and practitioners concerned with Australian Indigenous education and Health and Physical Education (HPE), as well as more broader educational equity and curriculum issues. Furthermore, a critical ethnographic case study is inherently instrumental through its mandate for social change.

The main modes of data production for the study included: document collation, observation and researcher notes, and individual and focus group interviews with stakeholders including students $(n=13)$, teachers of HE $(n=7)$, parents $(n=2)$, school administrators $(n=4)$, regional education staff $(n=2)$, community advisors in education and health $(n=2)$, and regional health professionals $(n=6)$. All of the HE teachers interviewed had between one to three years' teaching experience in the region, and one out of seven identified as Islander, compared to the remaining six who identified as Anglo-Australian.. All six of the regional health professionals identified as Islander. The case was crafted during five field visits by a single researcher over three years from the early reconstructions of thick notes and interview data in stages one and two to peer checking in stage three, and building system relations (stage four) to explanations of findings in stage five (Carspecken 1996, 44, 156, 203). The findings of this paper 
concentrate on the fields of knowledge recontextualisation and curriculum production across all sites of health education decision-making at this Torres Strait school.

\section{The social construction of pedagogic discourse in a state school in a remote Indigenous community.}

To investigate community participation in health education curriculum decision-making for the Indigenous Australian (Torres Strait Islander) girls in this study, Bernstein's (1990, 1996) social construction of pedagogic discourse informed the theoretical framework - specifically the understandings of power and control relations, classification and framing, and official and pedagogic recontextualising fields (see author citation suppressed, 2008). There are a growing number of researchers adopting Bernstein's work in analyses of Indigenous education in Australia. For example, Rose $(1999,2004)$ has analysed versions of 'relevant' reading curriculum produced by Western educators for Indigenous students, arguing that these curriculum models reproduce rather than interrupt educational inequity by denying access to powerful or esoteric knowledge and ways of knowing. In addition, Zevenbergen, Mousley and Sullivan (2004) investigated the inclusive learning approaches used by teachers in the construction of mathematics school knowledge.. Bernstein's theoretical oeuvre has also been adapted in other Australian research studies with marginalised groups, such as Samoan students, community members and education workers (author citation suppressed, 2001a \& b). These studies found that educational disadvantage was perceived as being the result of the arbitrary organisation of students, knowledge and spaces in schooling institutions, and the perceived differences between Australian schools and Samoan institutions.

Moreover, an increasing number of researchers have used Bernsteinian theory to analyse Health and/or Physical Education policy and curriculum decision-making in Australia (see for example: Macdonald \& Glover, 1997; Kirk, Macdonald \&Tinning, 1997); Glasby, 2000; Macdonald, lisahunter \&Tinning, 2007; Hay \& lisahunter, 2008; and Leow, Macdonald \& Hay, 2010). Much of this research has centred on pedagogic identities of HPE teachers, the power and control relations constituting the subjects of Health Education and Physical Education, as well as systems of evaluation or 
assessment of school knowledge (Bernstein, 1990, 1996). We hope to contribute to this growing body of work by focusing upon the contribution that a model of the pedagogic recontextualising field of health education can make for future curricula decisionmaking for Torres Strait Islander girls.

From a Bernsteinian (2000) perspective, recontextualisation refers to the relational processes of selecting and moving knowledge from one context to another, as well as to the distinctive re-organisation of knowledge as an instructional and regulative discourse. A recontextualising field or arena is a context or site comprised of actors/agents responsible for interpreting official policy discourses and on the basis of these interpretations producing texts for use by teachers and students in schools and classrooms. The politics of interpretation, from a Bernsteinian perspective, is governed by the recontextualising rule or principle, a principle comprised of instructional and regulative features. This principle regulates what knowledge and skills are selected, how these are organised (sequenced, paced) and evaluative criteria. The relational processes of knowledge selection and organisation are governed by regulative discourses, that is, specific models of what constitutes the 'good teacher, good teaching', assumptions about the Indigenous learner, learning styles and learn needs, and relevant and responsive education. Relational processes of knowledge selection and organisation are always governed by power and control relations. Power relations refer to the relative strength (weak or strong) of the symbolic boundaries demarcating what can be put together and kept apart. Control relations refers to the communication principles regulating who controls what, where, when and how in relation to classroom curriculum. If control relations are strong, the teacher has greater control over the selection, organisation and evaluative criteria of curriculum and there is little negotiation with students, parents and community members. Where control relations are weakened there is more space for negotiation over curriculum content, organisation and evaluation (Bernstein, 2000; see also Lundvall \& Meckbach, 2008).

See Figure 3 overpage. Fields of Knowledge Recontextualisation in Health Education for Torres Strait Islander girls, adapted from Bernstein (1990, 197). 


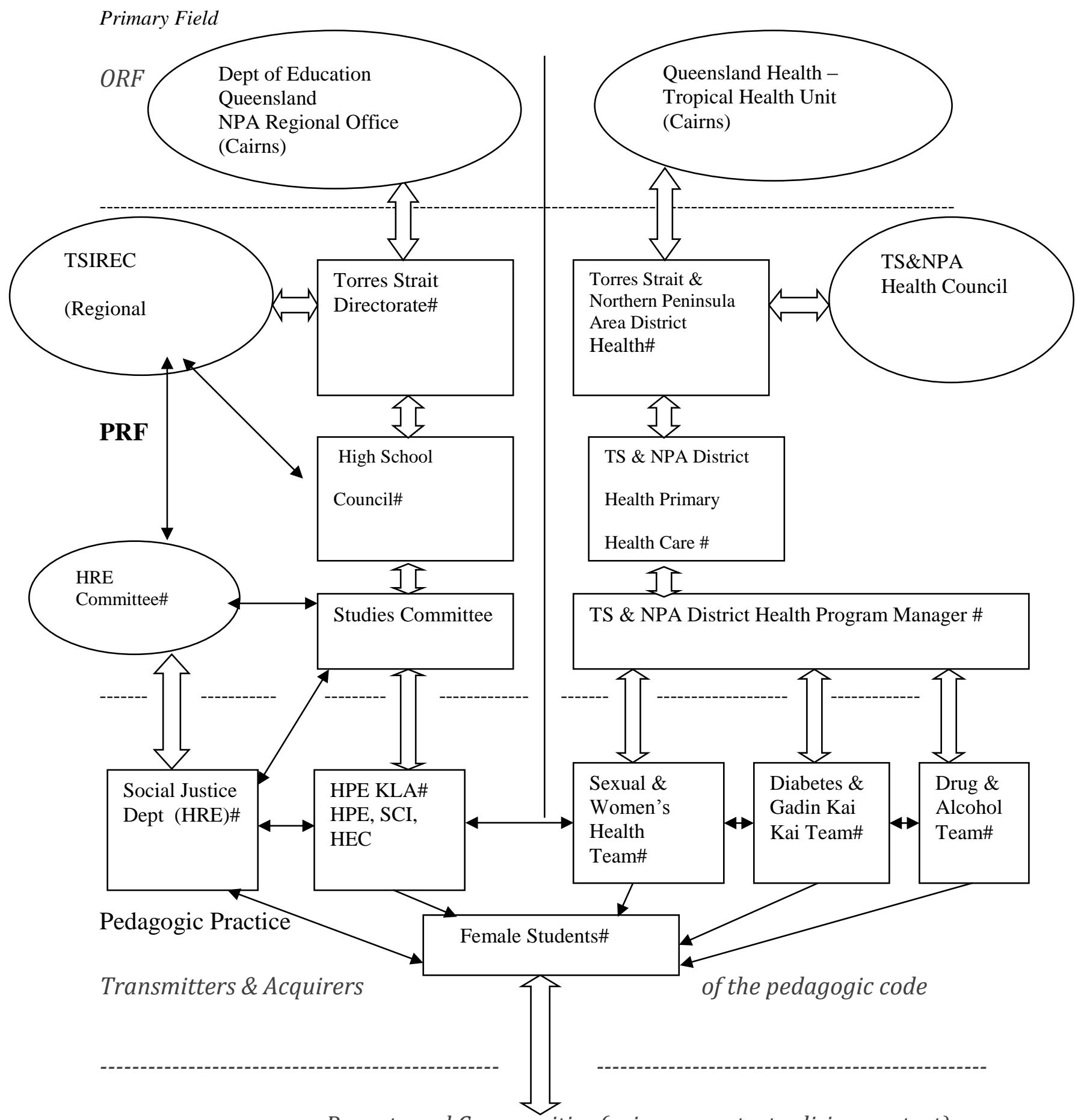

Parents and Communities (primary contextualising context)

KEY

$\longleftrightarrow$ Depicts weaker flows of communication between agents/locations

$\Longleftrightarrow$ Depicts stronger flows of communication between agents/ locations

Depicts strong boundaries between contents, agents and locations

------ Depicts weaker boundaries between contents, agents and locations

\# $\quad$ Sites of document analyses 
Figure Three illustrates that there were a lot of stakeholders participating in Indigenous health education in this school. Moreover, the figure illustrates that health education was taught and assessed across the curriculum subjects of HPE, Home Economics, Science and Human Relationships Education (HRE) What is distinctive about this representation of the way health education for girls was recontextualised is the existence of two arenas within the Official Recontextualising Fields (ORF) operating within the state departments of Education Queensland and Queensland Health. The solid line between the ORFs indicates the ironic operation of these departments almost in isolation from each other, except at the critical level of pedagogic practice where agents from various departments contribute to the pedagogic communciation of HE.. In this school, transmitters were not just teachers. The school had a history and contemporary practice of scheduling local health teams to teach important components of the HE curriculum in order to satisfy Ailan Kastom (Islander's customary ways)- that is, culturally responsive HPE for Indigenous girls (Sharp, 1997). For example, it was important for sexual health topics to be taught in single sex classes with same sex teachers - quite difficult to achieve when the entire HPE staff is male. The teachers needed to meet community demands for culturally responsive teaching and they achieved it through organised health worker participation. The HPE teachers, however, determined the selection, sequencing, pacing, and evaluative criteria, retaining power and control over the principles of pedagogic communication. This power was operationalised through requests for guest presenters, where the choice was essentially a case of please turn up on this day and teach this. This is represented in Figure Three through the weak arrows between the health worker teams and the HPE Key Learning Area (KLA) staff, strongly bounded by the solid line through the middle.

The arrows on the diagram indicate the strength of the social relations, that is, the strength of communication between agents and locations. The limited number of arrows across the central divide indicates limited communication across or between the arenas of state departments of health and education in relation to the provision of health education curriculum. However, within each arena within the ORF and Pedagogic Recontextualising Field (PRF), there was evidence of strong relationships between agents and stakeholders in the recontextualisation of Health Education (HE). For example, in Queensland Health, there was strong communication and weak boundaries 
between those state bodies responsible for articulating health policy into regional practice and the Indigenous community advisory groups (such as the Torres Strait \& Northern Peninsula Area TS\&NPA Health Council). This enabled Indigenous people at the local community level to exercise power over decision-making and take control off recontextualsing community priorities into health education practices. This was achieved through a Memoranda of Understanding (MOU) between parties involved in health education, dedicated Education Officers within the regional health department and a clear demarcation of responsibility for health education generally, and for specific health education components (such as women's health, men's health and dietetics).

A similar model of strong communication and weak boundaries between an Indigenous community advisory committee (the Human Relationships Education (HRE) parent committee), the transmitters (the teachers and health workers) and very importantly, the acquirers themselves (students) existed within the subject of HRE, which was delivered as a stand-alone subject separate to HPE. Parental power and control over curricular decision-making had been mandated since the 1980s as a compromise for allowing sexual health to be taught in state schools, following years of control by a very conservative state government. The HRE Coordinator also actively encouraged student input into curriculum decision-making through organised feedback mechanisms. This flow of communication meant that the subject of HRE was weakly bounded, taught by many staff and health workers whose subject identities were not invested in HPE, thus not affecting what was 'legitimated' in the HRE curriculum. The HRE Coordinator, who was not a HPE teacher, stated that when you've been here for a year, you basically get told you have to coordinate something, and I didn't want to be the Year 8 Coordinator. She was therefore open to community control over selection, sequencing and pacing of health education knowledge:

You can actually bring in a lot of community agencies such as the Sexual Health Team, Mura Kosker (Youth organisation) - all of those sorts of agencies have quite a big part in HRE. I can access anyone. Like, at the beginning of the year, there was a Dengue Fever outbreak so the community said "can we have some times, HRE times?" which were used to teach the students about Dengue fever (HRE Coordinator).

Yet, paradoxically, this teacher reinforced the pedagogic identity of Indigenous people as not 'knowers' by her views on parents' curriculum knowledge: 
...they could have certain input (like asking) what activities do you think would be good for the students to do, Yeah, but it's sometimes too if you are not a specialist in the area, it's difficult to make decisions too (HRE Coordinator).

The strong boundaries around the HPE department as depicted in Figure Three are well represented by this senior teacher's response to a question about seeking community power and control over curriculum decision-making:

I mean, if we really wanted to be responsive to what the community wants, then we would have to go out there and actually ask. But sometimes the timelines are a bit short, and we don't do that. We just go ahead with what we think is best. How's that for honesty? (Senior HPE Teacher).

An actionable finding for agents within the PRF in Education Queensland was the weak communication between the regional community advisory committee for education (Torres Strait Islands Regional Education Council - TSIREC) and various members of the ever-changing School Administration. The role of TSIREC in shaping relevant and responsive curricula for the Torres Strait region is clearly acknowledged in the State Government's Bound for Success (DET, 2000) policy document yet the formal communication and decision-making capacity of TSIREC within the school was completely at the mercy of the incumbent Principal (including four different principals over three years of data collection). The equivalent community committee on the other side of the diagram, the Health Council, benefitted from many members being both on the council and employed by Queensland Health. TSIREC had only two teacher members from the school, one in a Head of Department position, and one trainee teacher (under RATEP - Remote Area Teacher Education Program).

If space permitted, many more aspects of the recontextualisation of health education for Torres Strait Islander girls could be elaborated.. What we would like to summarise here are examples of partnership work in designing curriculum, and an awareness of the additional connections that need to be made outside of long-established internal school decision-making processes in order to develop relevant and responsive HE curriculum for Indigenous girls. This is one voice against the tide of 'educationally disadvantaged'projects that seem to capture the attention of agents within the upper echelons of the ORF.. Our purpose here is not to provide a definitive exemplar of how 
others should engage in curriculum negotiation to disrupt educational inequality. Following Evans \& Davies (2008:209) we acknowledge that there can be 'no singular programme of intervention' that would be relevant for all Indigenous girls. The experiences of Indigenous girls are likely to be vastly different depending on their social-economic status, geographic location and local community. What we propose is that the HPE curriculum needs to connect with the social, cultural and economic conditions that regulate people's lives and 'offer children and young people the "ability" in the form of confidence, competence and control of their "bodies" potential to deal with them effectively' (Evans \& Davies, 2008, 210).

\section{Discussion: Using lessons from Bernstein to deliver relevant and responsive Indigenous education}

The lessons to be learned from our study can be framed from Hughes' (foreword, in Mellor and Corrigan 2004) appraisal of what has gone wrong in the past - to stop focusing on problems, and particularly, Indigenous people as the problem. It is absolutely true that much research has been produced by non-Indigenous people that has failed to significantly improve educational outcomes for Indigenous people. However, it is also true that much good work is occurring around Australia that is not informing the government policy of the day and therefore not countering the unhelpful re-presentations of, and consequent research lens upon, 'educationally disadvantaged' Indigenous students and communities. These representations are unhelpful for two serious reasons - firstly, it allows government to continue to lament about 'what can we kind, benevolent, well-meaning White people do to "fix" Indigenous people', when there are clearly reported examples of educators and communities doing great things, sharing power and control over educational decision-making such as at the school featured in this paper (see also Hart 2003; Downey and Hart 2012; and www.whatworks.org.au). Obscuring successes in the discourse of "educational disadvantage" directs public attention away from demanding broader institutional responsibility to apply such learnings. Secondly, it fixes Indigenous pedagogic identities as deficient, uninformed, and dis-abled, further legitimating dominant discourses in the ORF which relegate Indigenous people, students and parents, as incapable of taking on 
the responsibility of curriculum decision-making that would enhance its relevance and responsiveness.

Indigenous educators do not require Bernsteinian theory to explain their context to them. They know it well, have been speaking and writing about it for decades, and stoically repeating themselves in the hope that community priorities will eventually articulate into policy, filter through the ORF into the PRF, reinforced by the actions, power and decisions made by PRF agents. We believe that the benefit of harnessing the work of Bernstein in Indigenous education will enable what Hughes (in Mellor and Corrigan, 2004) articulated to be necessary in future Indigenous research - to create a strong presence in the disciplines (not to be confused with being "defined" or "delimited" by those disciplines - see Nakata, 2007), and to direct attention to the inner workings of educational institutions such as schools. Indigenous educators, and those working and researching in Indigenous education, can use Bernstein's analytic concepts to speak powerfully and with an academic rigour that the Western academy acknowledges to turn public attention back towards those internal schooling processes and, consequently, the institutional responsibilities to enable Indigenous power and control over educational decision-making.

\section{Conclusion}

It has been our intention to demonstrate how recent debates in the Australian media and Government policy initiatives have reinforced a dominant and persistently negative discourse about 'educational disadvantage' when representing Aboriginal and Torres Strait Islander (Indigenous) students and educational outcomes. The educational disadvantage discourse focuses attention upon the social, material and cultural circumstances of students as the explanation for educational achievement (or lack thereof), where Indigenous students are defined more by what they 'lack' than what the Western schooling system fails to deliver (Nakata 2001; 2007). These discourses of lack permeate all school curriculum areas including HPE. Through an analysis of health education curriculum decision-making for Torres Strait Islander girls, we have shifted the research lens upon the power and control relations operating within schools, rather than external social relations, using principles of pedagogic discourse from Bernstein 
(1990, 1996, 2000). We have concluded that there is powerful potential for those working and researching in Indigenous education specifically, and social justice and equity issues generally, to utilise Bernstein's theoretical framework to analyse microlevel HPE curriculum politics. We argue that equity issues remain a key priority of HPE researchers and practitioners. The policy mantra of inclusion produces an illusion of addressing issues of equity and social justice (Singh \& Taylor, 2007). We propose that it is crucial for researchers to go beyond this illusory mantra of equity and analyse the power and control relations structuring the what, how, why and when of HPE school curriculum.. For it is these relations that position students unequally in terms of accessing privileged and privileging forms of HPE knowledge. Access and acquisition of powerful knowledge, ways of knowing and being, are central to the achievement of educational equality. At the same time, HPE researchers and practitioners need to be respectful of the powerful effects of both structure and agency in terms of 'making a difference' to educational disadvantage and strive for local, targeted and 'situated' solutions (Evans \& Davies, 2008, 209).

\section{References}

Abbott, R., Jenkins, D., Haswell-Elkins, M., Fell, K., Macdonald, D., \& Cerin, E. 2008. Physical activity of young people in the Torres Strait and Northern Peninsula Region: an exploratory study. Australian Journal of Rural Health 16 (5, 278-82.

Amade-Escot, C., \& O'Sullivan, M. (2007). Research on content in physical education: theoretical perspectives and current debates. Physical Education and Sport Pedagogy, 12(3), 185-204.

Australian Curriculum and Assessment Reporting Authority (ACARA). 2013. Draft Australian Curriculum: Health and Physical Education Foundation to Year 10. Retrieved 29.1.2013 from http://consultation.australiancurriculum.edu.au/.

Bernstein, B. 1971. Class, Codes and Control. Volume 1: Theoretical Studies Towards a Sociology of Language. London: Routledge and Kegan Paul.

Bernstein, B. 1975. Class Codes and Control. Volume 3: Towards a Theory of Educational Transmissions, London: Routledge and Kegan Paul.

Bernstein, B. 1990. The Structuring of Pedagogic Discourse. Volume 4. Class, Codes and Control. London: Routledge.

Bernstein, B. 1996. Pedagogy, Symbolic Control and Identity: Theory, Research, Critique. London: Taylor and Francis.

Bernstein, B. 2000. Pedagogy, Symbolic Control and Identity: theory, research and critique. New York: Rowman and Littlefield Publishers Inc.

Carspecken, P.F. 1996. Critical Ethnography in Educational Research: a theoretical and practical guide. New York: Routledge.

Carspecken, P.F. and Apple, M. 1992 Critical Qualitative Research: theory, methodology and practice. In M.D. Le Compte, W.L. Millroy \& J. Preissle (Eds.) 
The Handbook of Qualitative Research in Education. San Diego: Academic Press, 507-553.

Department of Education, Employment and Training (DEET). (1989). National Aboriginal and Torres Strait Islander Education Policy - First Triennium 1990 1992. Canberra: AGPS.

Department of Education, Employment and Workplace Relations (DEEWR). (2009). National Indigenous Education Statement. Canberra: Commonwealth of Australia. Retrieved 18.6.2010 from (http://www.deewr.gov.au/Indigenous/HigherEducation/Programs/Pages/Indigeno usEducationStatement.aspx.

Downey, P. and Hart, V. 2012. Teaching and Textual Spaces in Indigenous Education: A Murri School Perspective. In Introductory Indigenous Studies: The importance of knowing $2^{\text {nd }}$ Edition, eds. J. Phillips and J. Lampert, 97-113. Sydney: Pearson Education Australia.

Evans, J. 2013. Physical Education as porn! Physical Education and Sport Pedagogy, 18(1), 75-89.

Evans, J., \& Davies, B. 2008. The poverty of theory: class configurations in the discourse of Physical Education and Health (PEH). Physical Education and Sport Pedagogy, 13(2), 199-213.

Evans, J., Davies, B., \& Penney, D. (1997). Making Progress? Sport Policy, Women and Innovation in Physical Education. European Journal of Physical Education, 2(1), 39-59.

Glasby, P. M. 2000. Teacher Constructions of Health: A Case Study of School Health Education in Queensland. St Lucia: University of Queensland.

Glover, S. and Macdonald, D. 1997. Working with the Health and Physical Education Statement and Profile in Physical Education Teacher Education: case studies and implications. The ACHPER Healthy Lifestyles Journal 44, no. 3: 21-25.

Hart, V. 2003. Teaching Black and Teaching Back. Social Alternatives, 22: 12-6.

Hay, P.J. and lisahunter. 2006. Please Mr Hay, what are my poss(abilities)?: legitimation of ability through physical education practices. Sport, Education and Society 11, no.3: 293-310.

Hay, P. and Penney, D. 2009. Proposing conditions for assessment efficacy in physical education. European Physical Education Review 15: 389-405. DOI: $10.1177 / 1356336$ X09364294.

Herbert, J. 2006. "Owning the Discourse, Seizing the Power". In Proceedings of the Australian Association for Research in Education AARE 2005 Conference, Retrieved 22/6/2010 from http://www.aare.edu.au/05pap/her05217.pdf

Heslop, J. 1998. Making the Schools Relevant: School and Community in Partnership. In G. Partington (Ed.) Perspectives on Aboriginal and Torres Strait Islander Education. Katoomba: Social Science Press, 274-293.

Hughes, P. 2004. Foreword. In The Case for Change : A Review of Contemporary Research on Indigenous Education Outcomes". Australian Education Review, No. 47: iii-v.

Ketchell, J. 2012. Challenges and Opportunities of Leadership in Bound For Success (B4S) Schools. Leadership Bound for Success (B4S) Video. Brisbane: Department of Education and Training, Queensland. Available at http://www.learningplace.com.au/deliver/content.asp?pid=37942

Kirk, D., Macdonald, D. and Tinning, R. 1997. The social construction of pedagogic discourse in physical education teacher education in Australia. Curriculum Journal 8, no. 2: $271-298$. 
Leow, A., Macdonald, D. and Hay, P. 2010. The use of Bernstein's transmission context in policy analysis. Paper presented at the $6^{\text {th }}$ International Bernstein Symposium, Griffith University, South Brisbane, June 30 - July 3, 2010.

Lingard, B. 2011. Policy as numbers: ac/counting for educational research. Australian Educational Researcher, 38, 355-382.

Lundvall, S., \& Meckbach, J. 2008. Mind the gap: physical education and health and the frame factor theory as a tool for analysing educational settings. Physical Education and Sport Pedagogy, 13(4), 345-364.

Macdonald, D. and Glover, S. 1997. Subject Matter Boundaries and Curriculum Change in the Health and Physical Education Key Learning Area. Curriculum Perspectives 17, no. 1: 23 - 29.

Macdonald, D., Hunter, L., and Tinning, R. 2007. Curriculum construction: A critical analysis of Rich Tasks in the recontextualizing field. Australian Journal of Education 51, no. 2: 112-128.

Macdonald, D. 2011. Like a Fish in Water: Physical Education Policy and Practice in the Era of Neoliberal Globalization. Quest 63, 36-45.

MacPhail, A. 2007. Teachers' views on the construction, management and delivery of an externally prescribed physical education curriculum: Higher Grade Physical Education. Physical Education and Sport Pedagogy, 12(1), 43-60.

McCuaig, L., \& Hay, P. J. 2012. Principled pursuits of 'the good citizen' in health and physical education. Physical Education and Sport Pedagogy, iFirst Article, 116. doi: DOI:10.1080/17408989.2012.666793.

Mellor, S. and Corrigan, M. 2004. The Case for Change : A Review of Contemporary Research on Indigenous Education Outcomes. Australian Education Review, no. 47. Retrieved from http://research.acer.edu.au/aer/7 .

Moreton-Robinson, A. 2004. Whiteness, epistemology and Indigenous representation. In Whitening Race: Essays in social and cultural criticism, ed. A. MoretonRobinson, 75-88. Canberra: Aboriginal Studies Press.

Nakata, M. 1993. Cultural Education: For Us or For Them? In Indigenous Minorities and Education: Australian and Japanese Perspectives of their Indigenous Peoples, the Ainu, Aborigines and Torres Strait Islanders, eds. N. Loos and T. Osanai, 334-349. Tokyo: Sanyusha Publishing Co. Ltd.

Nakata, M. 2001. Another Window on Reality. In Teaching, Democracy and Diversity, ed. B. Osborne, 331-353. Altona, Vic: Common Ground Publishing.

Nakata, M. 2007. Disciplining the Savages, Savaging the Disciplines. Canberra: Aboriginal Studies Press.

Nyberg, G., \& Larsson, H. 2012. Exploring 'what' to learn in physical education. Physical Education and Sport Pedagogy(iFirst Article), 1-13. doi: DOI:10.1080/17408989.2012.726982.

Penney, D., Evans, J. and Taggart, J. 2005. Educational codes and inclusivity in Physical Education. Paper presented at the Australian Association of Research in Education (AARE) conference 'Creative Dissent: Constructive Solutions', Sydney, November 27-December 1, 2005.

Phillips, J. 2012. Indigenous Knowledge: Making Space in the Australian Centre. In Introductory Indigenous Studies in Education: The Importance of Knowing $2^{\text {nd }}$ Edition, eds. J. Phillips and J. Lampert, 1-17. Sydney: Pearson Education Australia.

Queensland Studies Authority (QSA). 2013. Health and Physical Education P-10 syllabus. Retrieved 29.1.2013 from http://www.qsa.qld.edu.au/7294.html. 
Rose, D. 1999. Culture, competence and schooling: approaches to literacy teaching in Indigenous school education. In Pedagogy and the Shaping of Consciousness, ed. F. Christie, 217-245. London: Cassell.

Rose, D. 2004. Sequencing and pacing of the hidden curriculum: how Indigenous learners are left out of the chain. In Reading Bernstein, Researching Bernstein, ed. J. Muller, B. Davies \& A. Morais. London: Routledge Farmer.

Singh, P., \& Taylor, S. 2007. A New Equity Deal for Schools: A Case Study of PolicyMaking in Queensland, British Journal of Sociology of Education, 28 (3),301315.

Sharp, N. 1997. No Ordinary Judgment. Canberra: Aboriginal Studies Press.

Smyth. J., Hattam, R., McInerney, P. and Lawson, M. 1997. Finding the 'enunciative space' for teacher leadership and teacher learning. Paper presented at the Australian Association for Educational Research (AARE), Brisbane 1997. Retrieved 19/10/2009 from www.aare.edu.au/97pap/smytj118.htm

Soliman, I. 1995. From Involvement to Participation: Six levels of school-community interaction. In B. Limerick \& H. Nielsen. (Eds.). School and Community Relations: Participation, Policy and Practice. Sydney: Harcourt Brace, 159-174.

Stake, R. 1995. Case Study. London: Kegan Paul.

Thomas, J. 1993. Doing Critical Ethnography. Newbury Park, CA: Sage Publications.

Stewart, J. 1998. The Empowerment of Indigenous Australians in Mainstream Education. The Australian Journal of Indigenous Education, 27 (2), 27-40.

Tripcony, P. 2000. The Most Disadvantaged? Indigenous Education Needs. New Horizons in Education, December: 59-81.

White, N. 2009. University-educated Indigenous women: their struggles and triumphs in their leadership journeys. In Indigenous Issues in Australian Universities. Research, Teaching, Support, eds. J. Frawley, M. Nolan and N. White, 95-105. Darwin, Charles Darwin University Press.

Williams. B.J., Hay, P.J. \& Macdonald, D. 2011 The outsourcing of health, sport and physical educational work: a state of play, Physical Education and Sport Pedagogy, 16 (4), 399-415. To link to this article: http://dx.doi.org/10.1080/17408989.2011.582492

Zevenbergen, R., Mousley, J. and Sullivan, P. 2004. Making the pedagogic relay inclusive for Indigenous Australian students in mathematics classrooms. International Journal of Inclusive Education, 8, (4) 391-405.

\section{Acknowledgements}

The authors would like to acknowledge the Traditional Owners upon whose lands the five campuses of our university are located: the Yagarabul, Yuggera, Jagera, Turrbal, Yugambeh and Kombumerri peoples, and that these have been sites of unbroken learning and knowledge exchange for thousands of years. We also acknowledge the Kala Lagaw Ya and Meriam peoples (Torres Strait Islanders) and the Kaurareg Aboriginal people of the lower Western Torres Strait who participated or have made the study possible. Lastly, thanks to the Oodgeroo Unit, Queensland University of Technology for providing the support and funding to complete this investigation. 